\title{
The analysis of gas evolved from casting powder during heating in the mold
}

\author{
Tomasz Kargul ${ }^{1}$ (C)
}

Received: 27 February 2019/Accepted: 9 June 2019/Published online: 17 June 2019

(c) The Author(s) 2019

\begin{abstract}
In this paper, the thermal stability of two commercial casting powders was assessed with respect to registered mass changes and evolved gas analysis using a combination of TG/DTA/EGA simultaneous thermal analysis methods. The experiments were conducted in a temperature range of $50 \div 1300{ }^{\circ} \mathrm{C}$, in an oxidation atmosphere, with a heating rate of $10 \mathrm{~K} \mathrm{~min}{ }^{-1}$. The results presented in the article perfectly fit into the research trend related to the emission of gases from powders, using for this purpose coupled TG/EGA techniques of thermal analysis. Thermogravimetric measurements together with simultaneous EGA analysis of gases released from the samples enable the identification of the main reactions responsible for mass disturbance. The main registered mass losses were associated with carbon oxidation and thermal decomposition of carbonates presented in investigated powders. Based on the DTA results, melting temperature, as well as other endo/ exothermal effects of reactions taking place in the system, was elaborated. The possibility of FactSage usage, to elucidate the influence of selected components on the viscosity of investigated casting powders, is also presented. On the basis of the conducted research, it was found that recorded mass disturbance was not associated with the evaporation of components affecting the viscosity of casting powder.
\end{abstract}

Keywords Mold flux powder · Scorialit · Accutherm · Continuous casting · TG-DTA EGA · Viscosity · FactSage

\section{Introduction}

The continuous casting of steel is the most popular technology of slab production, which provides good product quality and a high-efficiency process. Whether the casting proceeds without failure at the assumed efficiency depends on the correct selection of the process parameters as well as the materials used to support steel casting. Mold flux powders (casting powders) are among those wherein any instability in the thermal properties could lead to unwanted process disturbance and surface defects formation. At present, these are synthetic slags, with a chemical composition tailored to the requirements of various steel grades. In general, the conventional casting powders consist of components based on the $\mathrm{CaO}-\mathrm{SiO}_{2}-\mathrm{Al}_{2} \mathrm{O}_{3}$ system, with the addition of fluxes $\left(\mathrm{Na}_{2} \mathrm{O}, \mathrm{K}_{2} \mathrm{O}, \mathrm{B}_{2} \mathrm{O}_{3}, \mathrm{Li}_{2} \mathrm{O}_{3}\right.$,

Tomasz Kargul

tkargul@agh.edu.pl

1 AGH University of Science and Technology, Al. A. Mickiewicza 30, 30-059 Kraków, Poland
$\left.\mathrm{CaF}_{2}\right)$ and carbonaceous materials. The main reason to apply casting powder is to facilitate the extraction of the pre-solidified strand from the mold to the secondary cooling zone. The proper implementation of other important functions, such as lubrication, thermal insulation of liquid steel, refining of non-metallic inclusions, or heat extraction between the strand and the mold, depends on the stability of thermophysical properties that are controlled by the chemical composition [1-3].

After the casting powder is added to the mold and before liquid slag is formed, several reactions take place, accompanied by gas evolution in the system. The gasses released during casting could affect the performance and stability of the mold flux properties. The melting rate and viscosity of the casting powder should be monitored during the process to support good lubrication condition and minimize powder consumption. The main reactions being the source of gas emissions include

- moisture evaporation.

- thermal and/or carbothermic decomposition of carbonates. 
- oxidation of carbonaceous materials.

- evaporation of components with a low melting temperature.

- evaporation of fluorine compounds.

The moisture content in commercial powders depends on the storage conditions and ranges from 0.1 to $0.8 \%$. The casting powder, due to coming into contact with liquid steel, heats up and the moisture starts to evaporate. As has been reported in the literature, the humidity contained in the casting powder could become a substrate in the reaction (1)

$\mathrm{CaF}_{2}+\mathrm{H}_{2} \mathrm{O} \rightarrow \mathrm{CaO}+2 \mathrm{HF}_{(g)} \uparrow$

and react with $\mathrm{CaF}_{2}$ in the slag to form-dangerous for the environment-hydrogen fluoride [2, 4, 5].

Conventional casting powders contain a certain amount of alkali: $\mathrm{Na}_{2} \mathrm{O}(1-20 \%), \mathrm{K}_{2} \mathrm{O}(1-5 \%), \mathrm{Li}_{2} \mathrm{O}(0-4 \%)$ that is added in the form of carbonates or fluorides, due to their unstable solid oxide form. Carbonates are a source of gases released during thermal or carbothermic decomposition that proceeds according to reactions:

$$
\begin{aligned}
& \mathrm{Me}_{x} \mathrm{CO}_{3} \rightarrow \mathrm{Me}_{x} \mathrm{O}+\mathrm{CO}_{2(g)} \uparrow \\
& \mathrm{Me}_{x} \mathrm{CO}_{3}+\mathrm{C} \rightarrow \mathrm{Me}_{x} \mathrm{O}+2 \mathrm{CO}_{(g)} \uparrow
\end{aligned}
$$

Kawamoto et al. observed the important role of released gases in the explanation of the melting rate of the casting powder. According to the authors' findings, the released gases cause the mixing of the casting powder layer, which increases the melting rate [6]. On the other hand, the slow kinetics of the $\mathrm{Na}_{2} \mathrm{CO}_{3}$ decomposition reaction was given by Kim as a key factor decreasing the melting rate [7].

Conventional casting powders contain up to $20 \%$ of carbon particles, added in different forms: coke breeze, carbon black, or graphite [8-10]. Their presence hinders the agglomeration of the liquid phase, which is used to control the propagation of the liquid phase in the mold. The melting rate of casting powder could only be controlled until the free carbon is not consumed by the reaction with oxygen.

The gases appear in the mold also due to evaporation of low-melting components, such as $\mathrm{B}_{2} \mathrm{O}_{3}\left(450^{\circ} \mathrm{C}\right), \mathrm{K}_{2} \mathrm{O}$ $\left(740{ }^{\circ} \mathrm{C}\right)$, and $\mathrm{Na}_{2} \mathrm{O}\left(1132{ }^{\circ} \mathrm{C}\right)$. The experimental research conducted by Wan et al. concerning fluoride-free powder development, indicates a viscosity decrease with the increasing $\mathrm{Na}_{2} \mathrm{O}$ content in the slag [11]. Zhang et al. analyzed the ternary system $\mathrm{Na}_{2} \mathrm{O}-\mathrm{B}_{2} \mathrm{O}_{3}-\mathrm{SiO}_{2}$ to identify the main gaseous products formed above $1573{ }^{\circ} \mathrm{C}$. The results of their tests indicate that low-melting oxides can evaporate from the system in the form of $\mathrm{NaBO}_{2}$, $\left(\mathrm{NaBO}_{2}\right)_{2}$ and $\mathrm{B}_{2} \mathrm{O}_{3}$ [12].

Recently, many studies have been conducted to investigate the evaporation of fluorine compounds from casting powders. These compounds, due to high vapor pressure, can escape at a higher temperature from the liquid and form gases, such as $\mathrm{NaF},(\mathrm{NaF})_{2}, \mathrm{KF}, \mathrm{SiF}_{4}, \mathrm{HF}$, and $\mathrm{CaF}_{2}$ $[4,5,13]$. This is considered as a phenomenon with a negative impact on the environment, also causing a health hazard and other technological problems like the acidification of water in the secondary cooling zone.

Most of the research found in the literature, related to the emission of gases from casting powders, was carried out by thermogravimetry (TG). Only a few authors have chosen the oxidation atmosphere to better reflect the actual process conditions in their experiments. Görnerup et al. in his conference paper, published the thermal characterization of two commercial casting powders, where a DSC curve was used to investigate the process running during oxidation heating, in a temperature range of $\mathrm{RT} \div 1400{ }^{\circ} \mathrm{C}$. Their findings show that the large amount of gasses released after the powder was added to the surface of liquid steel could result in powder fluidization [14]. In the present research, no thermogravimetric results were presented. The course of gas-generating reactions (oxidation and decomposition of components) was described as an assumption based on the analysis of thermal effects registered on the DSC curve. Brandaleze et al. published TG analysis of three commercial casting powders, with different amounts of $\mathrm{CaF}_{2}$, analyzed in air in a temperature range above $800{ }^{\circ} \mathrm{C}$. The obtained results of TG experiments were explained by fluorine evaporation calculated in FactSage [5]. Similar experimental studies showing the real composition of the gas phase released from the casting powder during melting were not found in the literature.

Considering the above, basic research conducted on the properties of casting powders and their stability at high temperature and the detailed analysis of released gases are of particular importance for supporting continuous casting technology.

The aim of the conducted research was to analyze the course of the chemical reactions activated in the casting powder during heating in the mold and determination of the impact of chemical composition changes on casting powder viscosity.

The stability of thermal properties for two types of commercial casting powders has been assessed with respect to registered mass changes, thermal effects, and evolved gas analysis, using a combination of TG/DTA/EGA simultaneous thermal analysis methods $[15,16]$.

In the first part of the paper, the results of the numerical calculation in FactSage 7.2 were presented to elucidate the influence of selected components on the viscosity of investigated casting powders.

In the experimental part, the identification of the processes occurring in the samples was carried out based on the combined analysis of registered thermal effects, mass 
changes, and clarified by the online identification of gases released from the sample during oxidation heating.

\section{Sample characterization}

Two conventional casting powders with the brand names Scorialit SL470/Si and Accutherm ST-SP/222-DS were investigated. The average chemical composition of casting powders provided by its manufacturer is shown in Table 1 .

Both analyzed casting powders have similar basicity (BI: 0.85) and are used for the casting of low and medium carbon steels. The free carbon content as well as carbonates amounts vary in the analyzed samples. The $\mathrm{CO}_{2}$ content, given in Table 1, can be used to calculate the amounts of corresponding carbonates, and that is for MFP1: $6 \% \mathrm{Na}_{2}$ $\mathrm{CO}_{3}, 5.1 \% \mathrm{~K}_{2} \mathrm{CO}_{3}, 5.8 \% \mathrm{CaCO}_{3}$ and $13.5 \% \mathrm{Na}_{2} \mathrm{CO}_{3}, 1.3 \%$ $\mathrm{K}_{2} \mathrm{CO}_{3}, 2.2 \% \mathrm{MgCO}_{3}$ for MFP2.

For the investigated casting powders, the HSM tests and thermodynamic calculation, performed in order to determine the influence of temperature on liquid phase formation, was previously published by Drożdż [17]. The obtained results indicate differences in the melting dynamics of the analyzed powders as well as significant differences in the melting range of the samples described by hemisphere $\left(T_{\mathrm{H}}\right)$ and flow temperature $\left(T_{\mathrm{F}}\right)$.

\section{Viscosity at $1300{ }^{\circ} \mathrm{C}$}

In the mold gap, between a solid steel shell and mold walls, a thin layer of liquid powder acts as a lubricant reducing the friction forces and prevents the sticking of the shell to the mold walls. The pool formed at the surface of steel is a reservoir for liquid powder that fills the gap between the mold wall and solidified strand shell. The casting powder with very low viscosity easily penetrates the gap and provides for good lubrication of the shell but it causes a significant powder consumption. In the opposite, excessively high viscosity will not provide proper infiltration by liquid slag, which can lead to a very dangerous increase in friction forces and result in shell breakouts. It could be stated that viscosity and the amount of liquid slag are the parameters determining the lubrication conditions in the mold gap. The melting rate of mold flux powder as well as viscosity should be optimized to support the good lubrication condition of the strand and minimize powder consumption during steel casting. Taking into account the temperature profile in the mold, the viscosity of the mold flux at $1300{ }^{\circ} \mathrm{C}$ is commonly presented in the literature [11].

FactSage is useful software in the analysis and optimization of thermodynamic parameters of complex metallurgical systems using the Gibbs energy minimization procedure [18-20]. The program also offers the Viscosity module, working on the engine involving a thermodynamic description of the system using the Modified Quasichemical Model. The access to the FToxide thermodynamic database is necessary to perform the viscosity calculation. The model requires very few parameters that were optimized to fit the experimental data for pure oxides and selected binary and ternary systems. Then, the viscosities of a multicomponent system are predicted by the model within the experimental error limits. The chemical composition of casting powder could change during steel casting. It could be the result of component evaporation and the refining function of mold flux powder. Considering the possibility of the evaporation of selected components, such as $\mathrm{CaF}_{2}, \mathrm{Na}_{2} \mathrm{O}$, and $\mathrm{K}_{2} \mathrm{O}$, their impact on the viscosity of analyzed casting powders was compared.

In order to check the impact of selected components on viscosity, calculations were done in FactSage 7.2, using Melts database, and the results obtained for temperature $1300{ }^{\circ} \mathrm{C}$ are shown in Fig. 1 .

The obtained results indicate that the viscosity of both analyzed casting powders is sensitive to changes in chemical composition. The biggest changes in viscosity were obtained for different amounts of $\mathrm{CaF}_{2}$ and $\mathrm{Na}_{2} \mathrm{O}$. The amounts of these components could change during the process, causing an increase in viscosity and disturbing the infiltration of the liquid powder into the mold gap. The influence of $\mathrm{K}_{2} \mathrm{O}$ content could be neglected in case of MFP2. In the case of MFP1, the amount of $\mathrm{K}_{2} \mathrm{O}$ slightly changes the viscosity, but only below $4 \%$. The observed increase in viscosity, caused by the evaporation of components, should be considered as a self-limiting process

Table 1 The average chemical composition of the investigated casting powders

\begin{tabular}{lllllllllll}
\hline Sample & \multicolumn{3}{l}{ Chemical composition/mass\% } & & & \\
\cline { 2 - 10 } & $\mathrm{CaO}$ & $\mathrm{MgO}$ & $\mathrm{SiO}_{2}$ & $\mathrm{Al}_{2} \mathrm{O}_{3}$ & $\mathrm{Fe}_{2} \mathrm{O}_{3}$ & $\mathrm{Na}_{2} \mathrm{O}$ & $\mathrm{K}_{2} \mathrm{O}$ & $\mathrm{CaF}_{2}$ & $\mathrm{C}$ & $\mathrm{CO}_{2}$ \\
\hline Scorialit SL470/Si(MFP1) & 27.0 & - & 32.0 & 4.5 & 0.5 & 3.5 & 3.5 & 7.5 & 7.5 & 6.5 \\
Accutherm ST-SP/222-DS (MFP2) & 29.1 & 2.6 & 34.2 & 5.7 & 1.5 & 7.9 & 0.9 & 6.9 & 4.3 & 7.2 \\
\hline
\end{tabular}



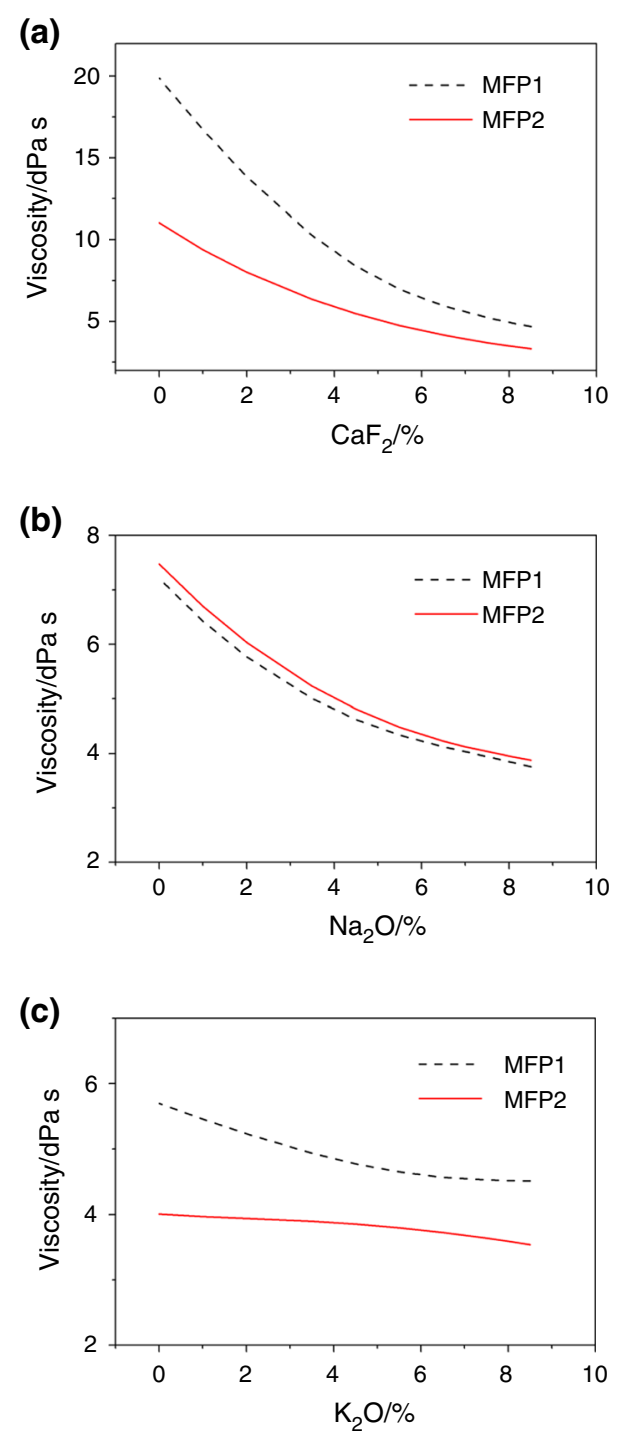

Fig. 1 The viscosity of casting powder calculated in FactSage, at $1300{ }^{\circ} \mathrm{C}$, for various amounts of: $\mathbf{a} \mathrm{CaF}_{2}, \mathbf{b} \mathrm{Na}_{2} \mathrm{O}, \mathbf{c ~} \mathrm{K}_{2} \mathrm{O}$

because the emission of gases from high viscosity liquids is more difficult.

The obtained simulation results confirmed that the chemical composition of the casting powder should be monitored during the continuous casting in order to ensure the correct implementation of its basic functions in the process.

\section{Experimental}

\section{Experimental conditions}

The main goal of the conducted research was to compare the thermal stability of two casting powders used in the continuous casting process. The evaluation of the thermal stability was conducted based on the results obtained for the TG and DTA experiments. The identification of the gases released from the sample allowed for clarifying the course of reactions affecting the mass of the samples. To better reflect the industrial process conditions, the tests were conducted in an atmosphere that allowed the free oxidation of components. The samples were analyzed in cylindrical alumina crucibles with a diameter of $5 \mathrm{~mm}$ and a volume of $0.3 \mu \mathrm{L}$, in a temperature range of $50 \div 1300{ }^{\circ} \mathrm{C}$. The average initial mass of the analyzed samples was $44 \mathrm{mg}$. The reference side, in case of all the measurements, was an empty crucible. The measurements were conducted with a standard heating rate of $10 \mathrm{~K} \mathrm{~min}^{-1}$, which has also been used by other authors investigating the thermal stability of casting powders [5]. An atmosphere of synthetic air $\left(\mathrm{N}_{2} / \mathrm{O}_{2} 99.999 \%, \mathrm{H}_{2-}\right.$ $\mathrm{O} \leq 3 \mathrm{ppm} \mathrm{mol}^{-1}, \mathrm{C}_{\mathrm{n}} \mathrm{H}_{\mathrm{m}} \leq 0.5 \mathrm{ppm} \mathrm{mol}^{-1}$ ) with a gas flow rate set to $1.67 \mathrm{~cm}^{3} \mathrm{~s}^{-1}$ was applied, which allowed free carbon and other components to be oxidized. The heating elements of the STA furnace were protected during the experiments by argon flow, which was also present in the measuring space of the sample. Each casting powder was tested several times to check the reproducibility, and the average results were presented.

The temperature calibration using standard metals In $\left(156.6^{\circ} \mathrm{C}\right)$, Bi $\left(271.4^{\circ} \mathrm{C}\right)$, $\mathrm{Al}\left(660.3{ }^{\circ} \mathrm{C}\right)$, and $\mathrm{Au}$ $\left(1064.2^{\circ} \mathrm{C}\right)$ was done prior to the measurement. TG and DTA signals were all corrected with a baseline curveregistered prior to empty crucibles in order to eliminate signals disturbance related to the measurement conditions.

\section{Methodology and equipment}

The use of simultaneous thermal analysis methods TG/ DTA/EGA makes it possible to investigate changes of different parameters of the sample during one experiment. This means that the measurement of sample mass changes can be recorded simultaneously under the same conditions with the thermal effects and identification of gases released from the sample. The experiments were carried out on two fully synchronized (time/temperature) devices, which are schematically shown in Fig. 2.

Netzsch STA 449 F3 Jupiter, with integrated microbalance (with accuracy $1 \mu \mathrm{g}$ ) and a TG-DTA sample carrier, was used to simultaneously register the thermal effects and mass loss of the investigated casting powders. The design of the device and its measuring ranges have been presented in the author's earlier publications [21, 22].

Evolved Gas Analysis (EGA) was conducted using a QMS Aëolos 403 quadrupole mass spectrometer connected directly to the outlet of STA furnace with quartz glass capillary, placed in a heated transfer line. The force forcing the transmission of gases through the capillary from STA 


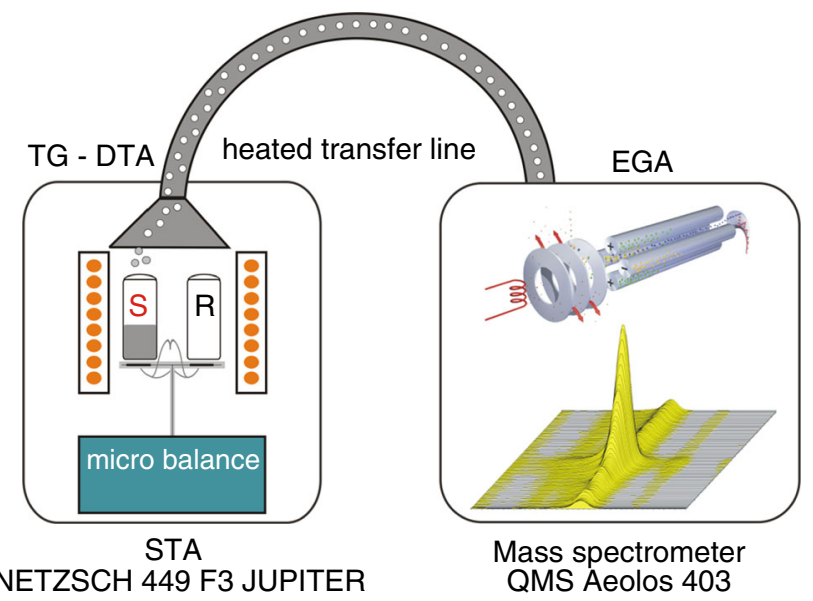

Fig. 2 Configuration of measuring equipment for the simultaneous analysis of gases released from casting powder

to the spectrometer ionization chamber was the pressure difference (STA $10^{3} \mathrm{mbar}>$ QMS $10^{-5} \mathrm{mbar}$ ). To reduce the possibility of the condensation of the gases in cold places, both the outlet of the STA furnace as well as a transfer line was heated to $300{ }^{\circ} \mathrm{C}$. The qualitative analysis of gas products consists in the identification and separation of ionized gases molecules, according to the $\mathrm{m} / \mathrm{z}$ ratio $(\mathrm{m}-$ ion mass, $\mathrm{z}$-charge) and the registration of ionic current generated in detector by ions with selected masses. Full synchronization of TG, DTA, and EGA signals enables the identification of gas products directly related to registered changes in sample mass and accompanying by the heat of reactions running in the sample. Initial tests were conducted in Scan Analog mode, where masses of appearing ions were observed in the range of $10 \div 110 \mathrm{u}$. The upper limit of the analyzed range was determined based on the mass of the heaviest of the ions expected in the system, and it was the molecular ion for $\mathrm{SiF}_{4} \mathrm{M}+$ : $104 \mathrm{u}$.

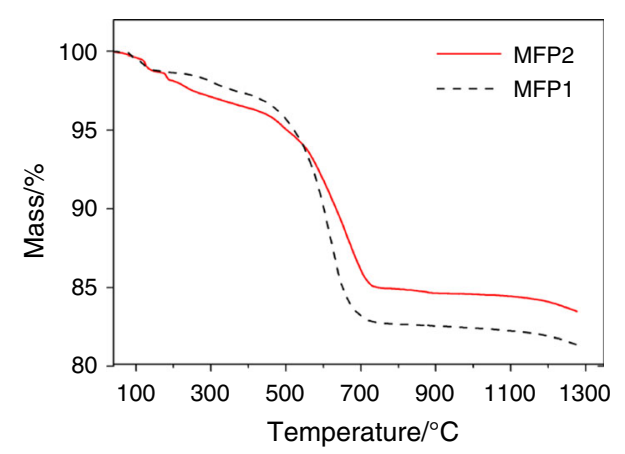

Fig. 3 The comparison of mass changes for analyzed casting powders

\section{Results and discussion}

The comparison of the registered mass changes for the investigated casting powders is shown in Fig. 3. In order to analyze the differences in the kinetics of running processes, the DTG curves are compared in Fig. 4. The DTA curves shown in Fig. 5 reflect the thermal characteristics of the processes occurring in the sample during heating.

In the case of both casting powders, three mass loss steps were registered in the temperature range up to $400{ }^{\circ} \mathrm{C}$. The recorded mass changes were accompanied by endothermic effects visible on the DTA curves (Fig. 5), which indicate this change in the sample mass was caused by moisture evaporation. To clarify the analysis of running processes, the profile of gases released from the samples was presented in Fig. 6. The main gases identified in the experiments were $\mathrm{H}_{2} \mathrm{O}$ (Fig. 6a) and $\mathrm{CO}_{2}$ (Fig. 6b). Evaporation of fluorine compounds or low-melting oxides was not confirmed in the performed experiments. In individual cases, a very slight increase in the ionic current for ions with a mass $\mathrm{m} / \mathrm{z} 42(\mathrm{NaF})$ was recorded. This may indicate the possibility of $\mathrm{NaF}$ compound evaporation, but it has not been possible to achieve the repeatability of these results. No release of carbon monoxide was found and the free carbon particles contained in the samples were oxidized completely to form $\mathrm{CO}_{2}$.

As shown in Fig. 6a, there is an increase in the ionic current registered for ions with $\mathrm{m} / \mathrm{z} 18$ and they were connected directly to the registered decrease of the sample mass and endothermic character of this process, which undoubtedly confirms water evaporation from the sample. Beyond the water, at the same temperature range, a small increase in the ionic current for carbon dioxide was registered. The sharp disorder generated by ions with $\mathrm{m} / \mathrm{z} 44$, with a peak temperature of $130{ }^{\circ} \mathrm{C}$, was repeatable for all of the investigated samples. In the analysis of the obtained results, it was assumed that the investigated samples could contain small amounts of contaminants of sodium and/or potassium bicarbonate $\left(\mathrm{NaHCO}_{3} / \mathrm{KHCO}_{3}\right)$, whose thermal

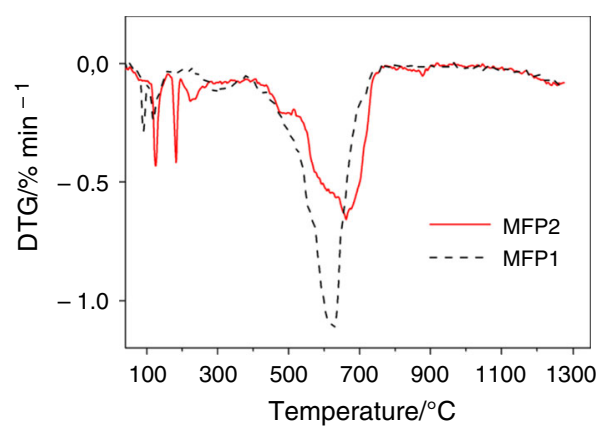

Fig. 4 The comparison of the rate of sample mass changes, registered for analyzed casting powders 


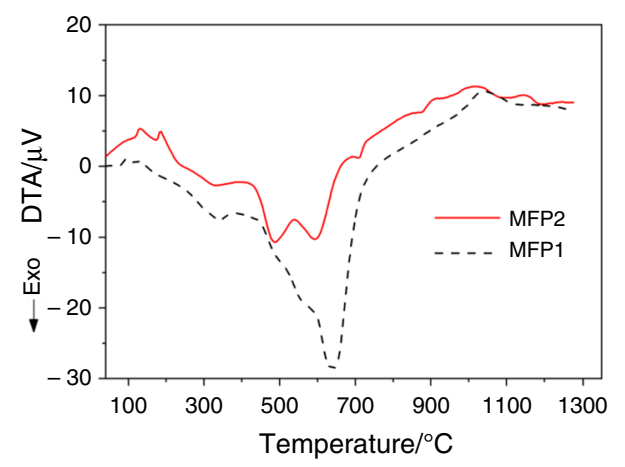

Fig. 5 The comparison of DTA curves registered for analyzed casting powders

(a)

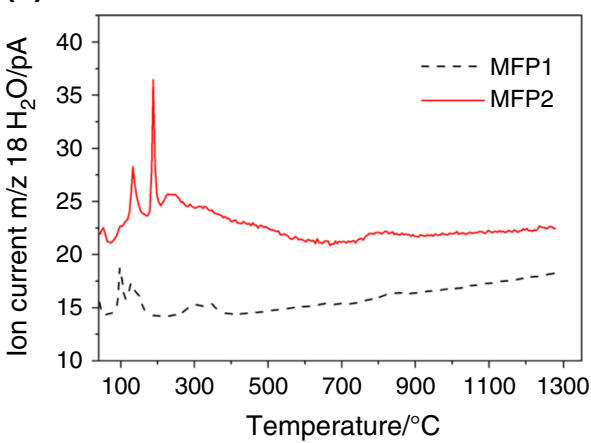

(b)

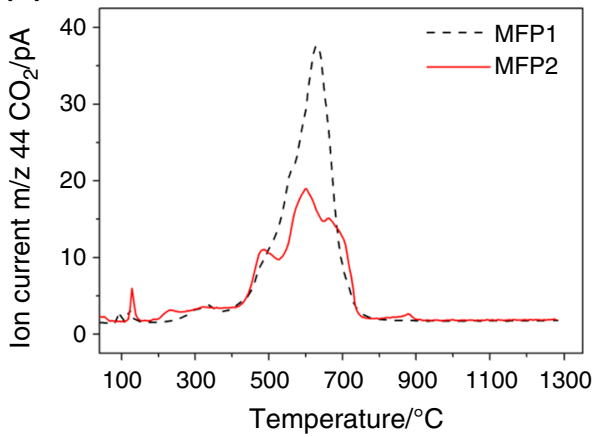

Fig. 6 MS curves showing the comparison of gases evolved from the samples: a water m/z $18\left(\mathrm{H}_{2} \mathrm{O}\right)$, b carbon dioxide $\mathrm{m} / \mathrm{z} 44\left(\mathrm{CO}_{2}\right)$

decomposition proceeds in the low temperature region with the simultaneous emission of water and carbon dioxide, according to Eq. 4

$2 \mathrm{MeHCO}_{3} \rightarrow \mathrm{Me}_{2} \mathrm{CO}_{3}+\mathrm{CO}_{2(g)} \uparrow+\mathrm{H}_{2} \mathrm{O}_{(g)} \uparrow$

Only in the case of MFP2 samples, another separate peak for $\mathrm{H}_{2} \mathrm{O}$ (not connected with simultaneous $\mathrm{CO}_{2}$ emission) was registered in a temperature range of $160 \div 200{ }^{\circ} \mathrm{C}$. The registered mass loss associated with the evaporation of water from the sample was $0.55 \%$.

The main mass change of the samples appeared during further heating, in the temperature range $400 \div 780{ }^{\circ} \mathrm{C}$.
For the MFP1 sample, the mass decreased in this range by $14.58 \%$ and this was accompanied by the exothermic disturbance visible on the DTA curve. The maximum temperature of this disorder was $650{ }^{\circ} \mathrm{C}$. The recorded heat released was associated with the oxidation of carbon particles, which was confirmed by the increase in $\mathrm{CO}_{2}$ released from the sample (Fig. 6b). All carbon particles from the sample were oxidized at this stage. Taking into account the mass balance, additional mass-reducing processes occurred during this mass lost step. The recorded increase in $\mathrm{CO}_{2}$ emission indicates the simultaneous course of carbon oxidation and carbonate decomposition. According to the literature, the carbonates present in casting powders could decompose in a wide temperature range of $400 \div 900{ }^{\circ} \mathrm{C}[1,17]$. The possibility of the carbothermic decomposition of carbonates (according to reaction 3) was rejected, as carbon monoxide was not identified in the gases emitted from the sample. In the higher temperature range, above $800{ }^{\circ} \mathrm{C}$, only an endothermic effect associated with sample melting was registered. The liquidus temperature for MFP1 casting powder, obtained as the maximum temperature of the last endothermic disturbance on the DTA curve, was $1038.3{ }^{\circ} \mathrm{C}$ and is consistent with the flow temperature obtained by Drożdż in HSM experiments $\left(1037^{\circ} \mathrm{C}\right)$ [17].

The DTA curve registered for MFP2 differs from what was registered for MFP1. A similar shape of the DSC curve was previously published by Görnerup et al. [14]. In the temperature range of $500 \div 580{ }^{\circ} \mathrm{C}$, combine exothermic disturbance, similar to this registered for the MFP2 sample, was analyzed as a two-stage combustion of carbonaceous materials: carbon black and coke dust. The exothermic effect registered for MFP2 on DTA curve, in a temperature range of $400 \div 780{ }^{\circ} \mathrm{C}$, was divided by running at the same time endothermic processes. The registered mass change of the sample in this range was $11.46 \%$, and the rate of mass changes was less rapid. Based on the analysis of gases released from the sample, the course of reactions 5-7

$\mathrm{C}+\mathrm{O}_{2(\mathrm{~g})} \rightarrow \mathrm{CO}_{2(\mathrm{~g})} \uparrow$

$\mathrm{Me}_{2} \mathrm{CO}_{3} \rightarrow \mathrm{Me}_{2} \mathrm{O}+\mathrm{CO}_{2(\mathrm{~g})} \uparrow$

$\mathrm{MeCO}_{3} \rightarrow \mathrm{MeO}+\mathrm{CO}_{2(\mathrm{~g})} \uparrow$

was considered in the analysis of this mass disturbance.

The evolved gas analysis confirms the gradual emission of $\mathrm{CO}_{2}$ from the MFP2 sample during this mass loss step. The registered $\mathrm{m} / \mathrm{z} 44\left(\mathrm{CO}_{2}\right)$ curve (Fig. 6b), the second peak with its maximum at $488{ }^{\circ} \mathrm{C}$, was considered in the analysis as a disorder associated with $\mathrm{MgCO}_{3}$ decomposition. The endothermic reaction slightly disturbed while running at the same time as the exothermic process of carbon combustion. The mass loss associated with this disorder was about 2\%, which corresponds to the 
calculated $\mathrm{MgCO}_{3}$ content in the sample. At $880{ }^{\circ} \mathrm{C}$, another single exothermic disorder was revealed on the DTA curve, running with the simultaneous emission of carbon dioxide from the sample. The change in the mass associated with the combustion of remaining carbon particles was $0.30 \%$. The further course of the DTA curve revealed only endothermic disorders related to sample melting. The liquidus temperature for MFP2 casting powder was elaborated as the maximum temperature of the last endothermic disorder revealed on DTA curve at $1148{ }^{\circ} \mathrm{C}$, and it corresponds to the final melting temperature $\left(1134{ }^{\circ} \mathrm{C}\right)$ obtained by Drożdż [17].

Taking into account the obtained results, it can be stated that viscosity of both analyzed casting powders should not be directly disturbed by running reactions. The gases emitted from the samples did not contain components, the loss of which, could significantly affect the viscosity. Observed differences in the course of individual reactions were associated with different content of carbon particles and carbonates in analyzed casting powders. The thermal effects registered on the DTA curves confirm differences in the dynamics of the processes occurring during samples melting. The rate of carbon combustion reaction is higher than thermal decomposition of carbonates. This could be also observed on DTG curves, showing differences in kinetic of mass changes for analyzed casting powders. The maximum ion current registered for carbon dioxide for MFP1, was twice this registered for MFP2, which is in line with the carbon content in the samples. The gases released during heating could have an impact on the melting rate. The liquidus temperature for the MFP1 sample was recorded at a temperature lower by $100{ }^{\circ} \mathrm{C}$ compared to MFP2. More detailed studies, taking into account different sample mass, should be carried out to confirm the effect of gases on the melting rate. Because MFP1 contains more free carbon particles, the heat generated during carbon combustion could also accelerate its melting rate.

In case of both casting powders, no exothermal effects were registered above $880{ }^{\circ} \mathrm{C}$, which means that all of the carbon particles were oxidized before the final samples melting. During the real casting process, mold flux powder is continuously fed into the mold, meaning that the carbon particles may come into contact with the previously molten fraction and control propagation of liquid phase, before the carbon is consumed in the reaction with oxygen.

The total registered mass decrease of samples $(18.44 \%$ for MFP1 and $16.46 \%$ for MFP2) should be taken into account in the calculation of the coefficient of casting powder consumption $Q$ s, according to Eq. 8 [8].

$Q_{\mathrm{S}}=f \cdot 7,6 \cdot Q_{\mathrm{t}} / R$

where $f$ denotes the share of the casting powder components forming liquid slag, $Q_{\mathrm{t}}$ is the consumption of powder in relation to the mass of steel produced $\left(\mathrm{kg} \mathrm{Mg}^{-1}\right)$ and $R$ is the coefficient describing the shape of the crystallizer. According to the obtained results, only $82 \div 84 \%$ of the initial mass of casting powders could be utilized to form liquid slag in the mold.

In the performed experiments, no emissions of fluorine or low-melting oxides were observed. This allows you to state that, for the considered experimental conditions, the mass of the samples was not disturbed by processes that could have a direct impact on the viscosity.

\section{Conclusions}

In the present paper, new results concerning gases emission from the casting powder during heating in the mold was presented. The results of simultaneous thermal analysis experiments (TG/DTA/EGA) performed for two grades of industrial casting powders (MFP1, MFP2) in temperature range $50 \div 1300{ }^{\circ} \mathrm{C}$ have been presented. The simulation results of the powder viscosity changes, made in the FactSage 7.2 program, were used to determine the effect of changes in the chemical composition on the stability of thermal properties. The main conclusions resulting from the conducted research can be summarized as follow:

- The recorded total mass loss of samples $(18.44 \%$ for MFP1 and $16.46 \%$ for MFP2) is of great importance for determining the degree of powder consumption in the process.

- The main reactions that occur during heating, affecting the mass of analyzed samples were identified.

- For both casting powders, the main mass disturbance, running in a temperature range of $400 \div 780{ }^{\circ} \mathrm{C}$, was caused by the oxidation of carbon particles and the thermal decomposition of carbonates, which was confirmed by the emission of $\mathrm{CO}_{2}$ from the samples and exo/endo thermal disorder registered on the DTA curves.

- The melting points for MPF1 and MFP2 were $1038.3^{\circ} \mathrm{C}$ and $1134{ }^{\circ} \mathrm{C}$, respectively. The obtained results were in good agreement with the previously published studies of other authors.

- According to TG/EGA results, no evaporation of $\mathrm{CaF}_{2}$ and $\mathrm{Na}_{2} \mathrm{O}$ in the analyzed temperature range was observed, which according to FactSage simulations results, could significantly affect the viscosity of the casting powders.

The application of the simultaneous thermal analysis method gives a new look at the processes affecting the mass of the casting powder, especially in the aspect of the gas phase composition released from the powder during melting in the mold. 
Acknowledgements This research was supported through the statutory funds of AGH UST, as part of Project No. 11.11.110.293.

Open Access This article is distributed under the terms of the Creative Commons Attribution 4.0 International License (http://creative commons.org/licenses/by/4.0/), which permits unrestricted use, distribution, and reproduction in any medium, provided you give appropriate credit to the original author(s) and the source, provide a link to the Creative Commons license, and indicate if changes were made.

\section{References}

1. Mills KC. Structure and properties of slags used in the continuous casting of steel: part 1 conventional mould powders. ISIJ Int. 2016;56:1-13.

2. Mills KC. Structure and properties of slags used in the continuous casting of steel: part 2 specialist mould powders. ISIJ Int. 2016;56:14-23.

3. Falkus J. An evaluation of the stability of mould flux properties in the process of continuous steel casting. Arch Metall Mater. 2017;62:885-9.

4. Persson M, Seetharaman S, Seetharaman S. Kinetic studies of fluoride evaporation from slags. ISIJ Int. 2007;47:1711-7.

5. Brandaleze E, Valentini M, Santini L, Benavidez E. Study on fluoride evaporation from casting powders. J Therm Anal Calorim. 2018;133:271-7.

6. Kawamoto $M$, Nakajima $K$, Kanazawa $T$, Nakai K. Design principles of mold powder for high speed continuous casting. ISIJ Int. 1994;34:593-8.

7. Kim J-W, Lee H-G. Thermal and carbothermic decomposition of Na2CO3 and Li2CO3. Metall Mater Trans B. 2001;32:17-24.

8. Mills KC, Fox AB, Li Z, Thackray RP. Performance and properties of mould fluxes. Ironmak Steelmak. 2005;32:26-34.

9. Benavidez E, Santini L, Martín A, Brandaleze E. Master decomposition curve of carbonaceous materials used in casting powders. J Therm Anal Calorim. 2018;133:695-701.
10. Singh D, Bhardwaj P, Yang YD, McLean A, Hasegawa M, Iwase $M$. The influence of carbonaceous material on the melting behaviour of mould powder. Steel Res Int. 2010;81:974-9.

11. Wen G, Sridhar S, Tang P, Qi X, Liu Y. Development of fluoridefree mold powders for peritectic steel slab casting. ISIJ Int. 2007;47:1117-25.

12. Zhang Z, Sridhar S, Cho J. An investigation of the evaporation of B2O3 and $\mathrm{Na} 2 \mathrm{O}$ in F-free mold slags. ISIJ Int. 2011;51:80-7.

13. Hill RG, Da Costa N, Law RV. Characterization of a mould flux glass. J Non Cryst Solids. 2005;351:69-74.

14. Görnerup M, Hayashi M, Däcker C, Seetharaman S. Mould fluxes in continuous casting of steel-characterization and performance tuning. In: VII Int Conf Molten Slags Fluxes Salts. 2004;745-52.

15. Jerzak W, Kargul T, Kuźnia M. Thermogravimetric and mass spectrometric analysis of powdered pine bark. Energy Sources, Part A Recover Util Environ Eff. 2018;40:2227-35.

16. Kargul T. Investigations of temperatures of phase transformations of low-alloyed reinforcing steel within the heat treatment temperature range. Arch Metall Mater. 2017;62:891-7.

17. Drozdz P. Analysis of the equilibrium state of flux powders in the mould during continuous casting of steel. Arch Metall Mater. 2015;60:263-8.

18. Kargul T, Falkus J. A hybrid model of steel refining in the ladle furnace. Steel Res Int. 2010;81:953-8.

19. Wielgosz E, Kargul T, Falkus J. Comparison of experimental and numerically calculated thermal properties of steels. In: Proceedings paper. In: METAL 2014: 23rd international conference on metallurgy and materials, Brno 2014.

20. Dziarmagowski M, Kargul T. Production of slag-forming materials in the steelmaking slag reduction process. Arch Metall Mater. 2009;54:137-42.

21. Wielgosz E, Kargul T. Differential scanning calorimetry study of peritectic steel grades. J Therm Anal Calorim. 2015;119:1547-53.

22. Kargul T, Wielgosz E, Falkus J. Application of thermal analysis tests results in the numerical simulations of continuous casting process. Arch Metall Mater. 2015;60:121-5.

Publisher's Note Springer Nature remains neutral with regard to jurisdictional claims in published maps and institutional affiliations. 